\title{
STRES PADA PENDUDUK LANJUT USIA YANG MENDERITA HIPERTENSI DIWILAYAH KERJA PUSKESMAS TABANAN II KABUPATEN TABANAN PERIODE SEPTEMBER- OKTOBER 2013
}

\author{
I.B Made Andy Wiraputra ${ }^{1}$ \\ Program Studi Pendidikan Dokter, Fakultas Kedokteran Universitas Udayana ${ }^{1}$
}

\section{ABSTRAK}

Meningkatnya jumlah populasi lanjut usia ini, maka permasalah kesehatan terkait pun juga akan meningkat. Masalah kesehatan jiwa adalah salah satu problem kesehatan yang sangat penting pada penatalaksanaan seorang lansia. Orang yang mengalami stres mempunyai risiko untuk hipertensi 2,5 lebih tinggi kali dibandingkan yang tidak mengalami stress. Pada bulan Mei 2013, 54\% lansia di wilayah kerja Puskesmas Tabanan II telah didiagnosa dengan hipertensi.

Penelitian ini bertujuan untuk mengetahui hubungan stres terhadap derajat hipertensi yang diderita penduduk lanjut usia yang berobat ke Puskesmas Tabanan II Kabupaten Tabanan. Penelitian dilakukan pada bulan September-Oktober 2013, menggunakan rancangan penelitian cross sectional. Pengumpulan data dalam penelitian ini ditempuh dalam dua tahapan kerja, data primer dilakukan dengan cara wawancara melalui kuesioner dari rumah ke rumah dan data sekunder diperoleh dari informasi yang tersedia di Puskesmas Tabanan II, Kabupaten Tabanan.

Hasil penelitian menunjukkan bahwa pada responden dengan status hipertensi grade I sebanyak 41 orang $(75,9 \%)$ mengalami stres sedangkan pada responden dengan status hipertensi grade II sebanyak 27 orang $(81,8 \%)$ mengalami stres. Hasil uji korelasi Kendall untuk variabel tingkat stres dengan derajat hipertensi menunjukkan nilai koefisien korelasi sebesar 0,069 dengan nilai $p=0,521$. Hasil ini menunjukkan adanya korelasi antara stres dan derajat hipertensi yang searah. Namun, harga koefisien korelasi antara stres dan derajat hipertensi menunjukkan hubungan yang sangat lemah antara stres dan derajat hipertensi $(0,069<0,2)$. Apabila dilihat dari harga $p=0,521(>0,05)$ maka tidak terdapat korelasi yang bermakna antara kedua variabel tersebut.

Kata kunci: lansia, stress, hipertensi

\section{INCIDENT STRESS IN ELDERLY PEOPLE SUFFERING HYPERTENSION IN TABANAN SECOND PRIMARY HEALTH CENTER'S REGION AT TABANAN REGENCY}

\section{ABSTRACT}

The growing number of the elderly population, so health related problems also will increase. Mental health concerns are among the most important health problems in the management of the elderly. From research was found that people who experience stress have a higher risk of developing hypertension, 2.5 times more than those who do not experience stress. In May 2013, 54\% of elderly people in the region in tabanan second primary health center's region at tabanan regency have been diagnosed with hypertension,.

This study aims to determine the relationship of stress on the degree of hypertension, that suffered by elderly people treated at in Tabanan second primary health center's region at Tabanan regency. The study carried out in September-October 2013, using a study design with cross sectional analysis. Data collection in the study was done in two stages of work, primary data through interviews conducted by questionnaires from house to house and secondary data obtained from the information available at primary health center's .

The results showed that the respondents with hypertension, grade I status as many as 41 people (75.9\%) experienced stress while respondents with hypertension, grade II status as many as 27 people (81.8\%) experienced stress. Kendall correlation test results for the variable stress levels with the degree of hypertension, showed a correlation coefficient of 0.069 with $p=0.521$. These results show a correlation between stress and the the degree of hypertension, in the same direction. However, the price of the 
correlation coefficient between stress and the degree of hypertension showed a very weak relationship between stress and the degree of hypertension, $(0.069<0.2)$. When viewed from the price of $p=0.521$ (> 0.05 ) so there is no significant correlation between the two variables.

Keywords: elderly, stress, hypertension

\section{PENDAHULUAN}

\section{Latar Belakang}

Pembangunan telah meningkatkan usia harapan hidup penduduk Indonesia, yang diiringi dengan meningkatnya jumlah dan persentase penduduk lanjut usia. Data statistik yang diambil dari Kantor Menteri Kependudukan/BKKBN menunjukkan bahwa penduduk lanjut usia Indonesia pada awal abad ke 21 ini diperkirakan adalah sekitar 15 juta orang dan pada ada tahun 2020 jumlah lansia diperkirakan akan meningkat sekitar $30-40$ juta orang $(11,2 \%$ dari total penduduk Indonesia). Diperkirakan 10 tahun ke depan struktur penduduk Indonesia akan berada pada struktur usia tua. Dengan meningkatnya jumlah populasi lanjut usia ini, maka permasalah kesehatan terkait pun juga akan meningkat. ${ }^{1,2,3}$

Penuaan adalah suatu keadaan dimana selalu berjalan beriringan disertai dengan gangguan fisik, social dan psikologi yang saling bertautan. ${ }^{2}$ Hal tersebut mengakibatkan masalah kesehatan baik umum dan khusus. pada lansia. Hal ini adalah salah satu problem kesehatan yang sangat penting pada penatalaksanaan seorang lansia

Kondisi lanjut usia mengalami berbagai penurunan dalam segala aspek, yang nantinya dapat memengaruhi kehidupan sosial. Hal itu biasanya bersumber dari munculnya stressor psikososial yang mana dapat menyebabkan stres dan apabila berkepanjangan dapat menuju masalah yang lebih serius yaitu depresi. Diperkirakan bahwa stres dan depresi pada tahun 2020 akan menjadi penyebab nomor dua dari disabilitas lansia di seluruh dunia. ${ }^{4,5,6}$

Stres dapat mengganggu fungsi saraf parasimpatik, fungsi otot polos, saraf simpatis, sekresi ekstern dan intern, dan kesadaran seseorang. ${ }^{7} \mathrm{Hal}$ tersebut dapat meningkatkan risiko hipertensi. Supargo dkk menyatakan hipertensi diderita lebih tinggi pada orang yang mengalami stres dibandingkan tidak. $^{8}$

Hipertensi sendiri faktor resiko utama penyakit jantung yang menjadi penyebab kematian terbanyak di dunia. Berdasarkan laporan Seventh Joint National Committee (JNC-7) prevalensi hipertensi di Indonesia sendiri pada umur 25-34 tahun sebesar 6,1\%, dan meningkat tajam pada golongan umur 35-44 tahun menjadi $14,7 \%$, dan mencapai $42,9 \%$ pada usia 55 tahun ke atas. ${ }^{9,10,11}$

Di wilayah kerja Puskesmas Tabanan II Kabupaten Tabanan yang terdiri dari 6 desa yaitu jumlah penduduk lanjut usia hampir $12 \%$ dari total populasi. Lanjut usia di wilayah ini sangat rentan terhadap stres karena terdapat beberapa karakteristik yang berkontribusi terhadap kondisi psikososial mereka, seperti rendahnya pendidikan yang rata-rata lulusan tingkat sekolah dasar, tingginya beban sosialekonomi dimana lebih dari 10\% rumah tangga masih tergolong dalam rumah tangga miskin, serta pelayanan kesehatan yang kurang spesifik untuk perawatan kesehatan lanjut usia dikarenakan tidak efektifnya posyandu lansia di wilayah ini. ${ }^{5}$

Pada bulan Mei 2013, 54\% lansia di wilayah kerja Puskesmas Tabanan II telah didiagnosa dengan hipertensi. Data Riskesdas 2007 menyatakan hipertensi menjadi penyakit terbanyak diderita lansia dan belum tertangani di Puskesmas Tabanan II dan cakupan pelayanan kesehatannya pun terbilang masih sangat rendah yaitu hanya sebesar $6,2 \%$.

Berdasarkan permasalahan tersebut dan dalam upaya peningkatan derajat kesehatan masyarakat khususnya penduduk lanjut usia maka diperlukan suatu gambaran hubungan stres yang terjadi pada lansia dengan tingginya angka kejadian hipertensi pada lansia di wilayah kerja Puskesmas Tabanan II Kabupaten Tabanan. Hal ini mengingat karakteristik penduduk lansia di wilayah kerja Puskesmas Tabanan Il Kabupaten Tabanan yang rentan terhadap stres dan juga stres sebagai salah satu faktor risiko dari hipertensi.

\section{METODE PENELITIAN}

Rancangan Penelitian

Penelitian ini menggunakan rancangan penelitian analitik dengan pendekatan cross sectional. Hasil penelitian berupa data deskriptif kuantitatif yang akan dianalisa secara analitik.

\section{Tempat dan Waktu Penelitian}


Penelitian ini dilakukan di wilayah kerja Puskesmas Tabanan II, Kecamatan Tabanan, Kabupaten Tabanan tanggal 15 September hinga 15 Oktober 2013

\section{Populasi dan Sampel}

Populasi dalam penelitian ini adalah penduduk yang berusia $\geq 60$ tahun di wilayah kerja Puskesmas Tabanan II, Kecamatan Tabanan, Kabupaten Tabanan.

Sampel yang diunakan adalah subyek orang dewasa yang datang ke poli umum Puskesmas Tabanan II pada tanggal 15 September hingga 15 Oktober 2013 dipilih secara non random sampling sampai tercapai sejumlah subyek yang memenuhi besar sampel minimal, yaitu 75 sampel. Kriteria Inklusi adalah penduduk di wilayah kerja Puskesmas Tabanan II yang berumur $\geq 60$ tahun yang tercatat dalam catatan kependudukan di masing-masing banjar dan memiliki alamat yang lengkap dan yang mengalami stres sesuai skala DASS atau hipertensi sesuai kriteria JNC VII dan/atau keduanya dan bersedia menjadi responden penelitian. Kriteria Eksklusi adalah penduduk berumur $\geq 60$ tahun yang berada di luar wilayah kerja, tidak dapat diwawancara karena alasan fisik dan komunikasi, atau meninggal di wilayah kerja Puskesmas Tabanan II.

\section{Definisi Operasional}

Stress didefinisikan sebagai gangguan atau kekacauan emosional yang disebabkan oleh faktor dari luar dan masalah itu menyebabkan perasaan tertekan, murung, bingung, cemas, berdebar-debar, rasa marah, dendam, rasa takut, rasa bersalah. Tekanan darah tinggi (hipertensi) didefinisikan sebagai Tekanan darah yang lebih tinggi dari normal, dengan menggunakan criteria JNC VII yaitu tekanan darah sistole $\geq 140 \mathrm{mmHg}$ dan/atau tekanan darah diastole $\geq 90 \mathrm{mmHg}$

\section{Teknik Pengumpulan dan Analisis Data}

Pengumpulan data primer dilakukan dengan cara wawancara melalui kuesioner dari rumah ke rumah. Sebelum wawancara dilakukan, responden dimintai persetujuan terlebih dahulu merujuk pada prinsip dan etika penelitian kedokteran. Data sekunder seperti data geografi wilayah, demografi penduduk secara umum dan data lainnya yang mendukung diambil dari informasi yang tersedia di Puskesmas Tabanan II.
Hasil penelitian dianalisis secara univariat dan bivariat. Pengolahan dan analisis data dilakukan secara manual dan komputerisasi dengaan menggunakan SPSS Version 16.0.

\section{HASIL PENELITIAN}

\section{Karakteristik Responden}

Berdasarkan hasil analisis rata-rata usia responden secara keseluruhan adalah 67,48 $\pm 6,310$ tahun dengan usia minimal 60 tahun dan usia maksimal 87 tahun. Proporsi responden berjenis kelamin laki-laki lebih kecil (36,8\%) dibandingkan dengan perempuan (63,2\%). Sebagian besar responden $(51,7 \%)$ memiliki tingkat pendidikan rendah. Mayoritas responden sudah tidak bekerja $(65,5 \%)$. Responden yang sudah menikah dan masih memiliki pasangan sebesar 60,9\%, sementara yang sudah berstatus duda/janda sebanyak 39,1\%. Hasil penelitian juga menunjukkan bahwa dari 87 orang subyek penelitian 54 orang $(62,1 \%)$ memiliki hipertensi grade I, 33 responden $(37,9 \%)$ memiliki hipertensi grade II.

\section{Gambaran Derajat Hipertensi dan Karakteristik Responden}

Pada saat pemeriksaan didapatkan lebih dari $50 \%$ responden mengalami hipertensi grade I. Hasil pemeriksaan tekanan darah sistolik rata-rata adalah $150,69 \pm 13,1$ dan tekanan darah diastolik rata-rata adalah $92,87 \pm 12,095$

\section{Gambaran Stres dan Karakteristik Responden}

Pengukuran dilakukan dengan menggunakan tes GDS yang spesifik untuk lansia. Hasil menunjukkan pasien yang memiliki penyakit hipertensi sebagian besar berada dalam status stres $(78,2 \%)$

\section{Hubungan Antara Stres dan Derajat Hipertensi Pada Pasien yang Berobat di Puskesmas Tabanan II}

Terlihat bahwa pada responden dengan status hipertensi grade I sebanyak 41 orang (75,9\%) mengalami stres sedangkan pada responden dengan status hipertensi grade II sebanyak 27 orang $(81,8 \%)$ mengalami stres. Hasil uji korelasi Kendall untuk variabel tingkat stres dengan derajat hipertensi menunjukkan nilai koefisien korelasi sebesar 0,069 dengan nilai $p=0,521$

Tabel 1. Karakteristik Responden

Karakterteristik Responden Jumlah Persentase (\%)




\begin{tabular}{|c|c|c|}
\hline & ( $\mathrm{N}=87$ orang) & \\
\hline Usia & 87 & 100 \\
\hline$=67,48$ & & \\
\hline Std. deviasi & & \\
\hline Minimum & & \\
\hline Maksimum $=87$ & & \\
\hline Mode & & \\
\hline Range & & \\
\hline Ratio skewness $=3,21$ & & \\
\hline Ratio kurtosis $=0,234$ & & \\
\hline \multicolumn{3}{|l|}{ Jenis Kelamin } \\
\hline Laki-laki & 32 & 36,8 \\
\hline Perempuan & 55 & 63,2 \\
\hline \multicolumn{3}{|l|}{ Tempat Tinggal } \\
\hline Denbantas & 14 & 16,1 \\
\hline Wanasari & 16 & 18,4 \\
\hline Sesandan & 18 & 20,7 \\
\hline Subamia & 13 & 14,9 \\
\hline Tunjuk & 10 & 11,5 \\
\hline Buahan & 16 & 18,4 \\
\hline \multicolumn{3}{|l|}{ Tingkat Pendidikan } \\
\hline Tidak sekolah & 33 & 37,9 \\
\hline SD/sederajat & 45 & 51,7 \\
\hline SMP/sederajat & 9 & 10,3 \\
\hline SMA/sederajat & 0 & 0 \\
\hline PT/sederajat & 0 & 0 \\
\hline \multicolumn{3}{|l|}{ Pekerjaan } \\
\hline Tidak bekerja & 57 & 65,5 \\
\hline Bekerja & 30 & 34,5 \\
\hline \multicolumn{3}{|l|}{ Status Perkawinan } \\
\hline Belum menikah & 0 & 0 \\
\hline Menikah & 53 & 60,9 \\
\hline Duda/janda & 34 & 39,1 \\
\hline \multicolumn{3}{|l|}{ Derajat Hipertensi } \\
\hline Hipertensi grade I & 54 & 62,1 \\
\hline Hipertensi grade II & 33 & 37,9 \\
\hline \multicolumn{3}{|l|}{ Stres } \\
\hline Tidak stres & 19 & 21,8 \\
\hline Stres & 68 & 78,2 \\
\hline
\end{tabular}

Hasil ini menunjukkan adanya korelasi antara stres dan derajat hipertensi yang searah. Artinya, semakin tinggi derajat stress seseorang maka semakin tinggi derajat hipertensi yang dideritanya. Namun, harga koefisien korelasi antara stres dan derajat hipertensi menunjukkan hubungan yang sangat lemah antara stres dan derajat hipertensi $(0,069<0,2)$. Apabila dilihat dari harga $p=0,521(>0,05)$ maka tidak terdapat korelasi yang bermakna antara kedua variabel tersebut.

\section{Pembahasan}

Subjek penelitian memiliki rata-rata usia $67,48 \pm$ 6,310 tahun dengan usia minimal 60 tahun dan usia maksimal 87 tahun dimana ini sesuai dengan kriteria lanjut usia yang berada $\geq 60$ tahun dan angka harapan hidup masyarakat Indonesia yaitu 65 tahun. Dilihat dari nilai ratio skewness dimana tidak berada dalam rentang -2 sampai dengan +2 maka sebaran/distribusi data untuk usia tidak normal. Skewness berkaitan dengan lebar kurve yang mana pada penelitian ini rentang data mencapai 27 . Walaupun nilai ratio 
kurtosis menunjukkan distribusi data yang normal, namun menilik pada nilai ratio skewness maka disimpulkan bahwa sebaran data usia pada penelitian ini tidak terdistribusi dengan normal.

Tabel 2 Gambaran Derajat Hipertensi dan Karakteristik Responden

\begin{tabular}{|c|c|c|c|c|c|c|}
\hline \multirow[t]{2}{*}{ Karakteristik Responden } & \multicolumn{2}{|c|}{ Hipertensi grade I } & \multicolumn{2}{|c|}{ Hipertensi grade II } & \multicolumn{2}{|c|}{ Total } \\
\hline & & $\%$ & & $\%$ & & $\%$ \\
\hline Hasil Pengukuran & 54 & 62,1 & 33 & 37,9 & 87 & 100 \\
\hline \multicolumn{7}{|l|}{ Usia } \\
\hline$<67$ tahun & 32 & 65,3 & 17 & 34,7 & 49 & 100 \\
\hline$\geq 67$ tahun & 22 & 57,9 & 16 & 42,1 & 38 & 100 \\
\hline \multicolumn{7}{|l|}{ Jenis Kelamin } \\
\hline Laki-laki & 22 & 68,8 & 10 & 31,2 & 32 & 100 \\
\hline Perempuan & 32 & 58,2 & 23 & 41,8 & 55 & 100 \\
\hline \multicolumn{7}{|l|}{ Tempat Tinggal } \\
\hline Denbantas & 8 & 57,1 & 6 & 42,9 & 14 & 100 \\
\hline Wanasari & 8 & 50,0 & 8 & 50,0 & 16 & 100 \\
\hline Sesandan & 12 & 66,7 & 6 & 33,3 & 18 & 100 \\
\hline Subamia & 7 & 53,8 & 6 & 46,2 & 13 & 100 \\
\hline Tunjuk & 5 & 50,0 & 5 & 50,0 & 10 & 100 \\
\hline Buahan & 14 & 87,5 & 2 & 12,5 & 16 & 100 \\
\hline \multicolumn{7}{|l|}{ Stres } \\
\hline Tidak stres & 13 & 68,4 & 6 & 31,6 & 19 & 100 \\
\hline Stres & 41 & 60,3 & 27 & 39,7 & 68 & 100 \\
\hline
\end{tabular}

Dilihat dari jenis kelamin sebagian besar responden berjenis kelamin perempuan (63,2\%). Hal ini sesuai dengan data dari Komisi Nasional Lanjut Usia (2010) yang menyebutkan bahwa jumlah lansia perempuan lebih banyak dibandingkan jumlah lansia laki-laki yang disebabkan oleh usia harapan hidup perempuan yang lebih tinggi dari laki-laki.

Responden berasal dari keenam desa yang tercakup dalam wilayah kerja Puskesmas Tabanan II Kabupaten Tabanan dengan distribusi data yang normal dilihat dari grafik histogramnya yang berbentuk lonceng.

Tingkat pendidikan responden sebagian besar tidak sekolah $(37,9 \%)$ dan pernah bersekolah pada tingkat SD (51,7\%). Data ini sesuai dengan hasil
Susenas (2009) yang memperlihatkan pendidikan penduduk lansia yang relatif rendah/ tingkat pendidikan lansia yang masih rendah ini terjadi di semua provinsi, termasuk Bali $(47,29 \%)$. Bali bahkan menduduki peringkat kedua setelah Nusa Tenggara Barat dilihat dari angka lansia yang tidak/belum pernah bersekolah tertinggi.

Hasil status pekerjaan dimana sebagian besar responden $(65,5 \%)$ tidak memiliki pekerjaan tidak sesuai dengan data hasil Sakernas (2009) yang menyatakan hampir separuh $(47,44 \%)$ lansia di Indonesia memiliki pekerjaan. Menurut data yang sama, sektor pertaniaan masih menjadi tumpuan sebagian besar pekerja lansia (66,14\%).

Tabel 3 Gambaran Stres dan Karakteristik Responden

\begin{tabular}{|c|c|c|c|c|c|c|}
\hline \multirow[t]{2}{*}{ Karakteristik Responden } & \multicolumn{2}{|c|}{ Tidak Stres } & \multicolumn{2}{|c|}{ Stres } & \multicolumn{2}{|c|}{ Total } \\
\hline & & $\%$ & & $\%$ & & $\%$ \\
\hline Hasil Pengukuran & 19 & 21,8 & 68 & 78,2 & 87 & 100 \\
\hline \multicolumn{7}{|l|}{ Usia } \\
\hline$<67$ tahun & 13 & 26,5 & 36 & 73,5 & 49 & 100 \\
\hline$\geq 67$ tahun & 6 & 15,8 & 32 & 84,2 & 38 & 100 \\
\hline
\end{tabular}




\begin{tabular}{lcccccc}
\hline $\begin{array}{l}\text { Jenis Kelamin } \\
\text { Laki-laki }\end{array}$ & 9 & 28,1 & 23 & 71,9 & 32 & 100 \\
$\quad$ Perempuan & 10 & 18,2 & 45 & 81,8 & 55 & 100 \\
\hline Tempat Tinggal & & & & & & \\
$\quad$ Denbantas & 5 & 35,7 & 9 & 64,3 & 14 & 100 \\
$\quad$ Wanasari & 3 & 18,8 & 13 & 81,2 & 16 & 100 \\
Sesandan & 3 & 16,7 & 15 & 83,3 & 18 & 100 \\
Subamia & 2 & 15,4 & 11 & 84,6 & 13 & 100 \\
$\quad$ Tunjuk & 3 & 30,0 & 7 & 70,0 & 10 & 100 \\
$\quad$ Buahan & 3 & 18,8 & 13 & 81,2 & 16 & 100 \\
\hline Derajat Hipertensi & & & & & & \\
$\quad$ Hipertensi grade I & 13 & 24,1 & 41 & 75,9 & 54 & 100 \\
$\quad$ Hipertensi grade II & 6 & 18,2 & 27 & 81,8 & 33 & 100 \\
\hline
\end{tabular}

\begin{tabular}{|lll|r|r|}
\hline & & \multicolumn{1}{c|}{$\begin{array}{c}\text { derajat_ } \\
\text { hipertensi }\end{array}$} & \multicolumn{1}{c|}{ stres } \\
\hline Kendall's tau_b & derajat_hipertensi & Correlation Coefficient & 1.000 & .069 \\
& & & .521 \\
& & Sig. (2-tailed) & 87 & 87 \\
\cline { 2 - 5 } & N & .069 & 1.000 \\
& Stres & Correlation Coefficient & .521 & \\
& Sig. (2-tailed) & 87 & 87 \\
& $\mathrm{~N}$ & & \\
\end{tabular}

Responden yang berstatus menikah sebesar $60,9 \%)$ sejalan dengan data dari Komisi Nasional Lanjut Usia (2010) yaitu 59,24\% lansia berstatus menikah, 39,78\% lansia berstatus cerai baik cerai mati maupun cerai hidup, dan $0,97 \%$ sisanya belum/tidak menikah.

Pada saat pemeriksaan ditemukan 62,1\% responden berada dalam status hipertensi grade I dimana tekanan darah sistolik responden antara 140 $\mathrm{mmHg}$ - $159 \mathrm{mmHg}$ dan atau tekanan darah diastolik pasien berada pada rentang $90 \mathrm{mmHg}-99 \mathrm{mmHg}$ sesuai kriteria JNC VII. Hal ini tidak sejalan dengan teori semakin tinggi umur seseorang maka semakin tinggi tekanan darahnya (Wilkinson, 2007). Pada penelitan ini baik penduduk yang berusia $>67$ tahun maupun $\geq 67$ tahun (sebagai nilai patokan digunakan nilai rata-rata) sama-sama lebih banyak berada pada rentang status hipertensi grade I.

Sebesar 78,2\% responden mengalami stres. Dari 87 responden penelitian, hanya 19 responden yang tidak mengalami stres. Hal ini menunjukkan bahwa lansia sangat rentan dengan paparan stres. Pada semua variabel, responden cenderung menunjukkan adanya gejala-gejala stres.

Analisis menunjukkan ada hubungan namun tidak bermakna antara stres dengan derajat hipertensi yang diderita oleh lansia. Tingkat keeratan hubungan antara stres dengan derajat hipertensi sangat lemah berdasarkan nilai koefisien korelasi (r) sebesar 0,069. Penelitian serupa yang pernah dilakukan oleh Supargo dkk dimana mendapatkan hasil bahwa risiko lebih tinggi 2,5 didapatkan pada orang yang mengalami stres dibandingkan dengan orang yang tidak stres tidak dapat dibuktikkan melalui penelitian ini karena tidak ditelitinya prevalensi hipertensi itu sendiri. Walaupun demikian pada penelitian ini tetap terdapat korelasi searah antara stres dan hipertensi yang sangat lemah dan tidak bermakna $(p>0,05) .1,5,6$

\section{Simpulan}

Berdasarkan simpulan diatas, dapat dirumuskan saran penelitian sebagai berikut: Perlu dilakukannya penelitian lebih mendalam mengenai kaitan stres dan hipertensi (tidak hanya derajat hipertensinya saja) dengan model dan sampel penelitian yang lebih dekat dengan populasi. Diharapkan agar Puskesmas Tabanan II dapat mengadakan upaya pencegahan di berbagai tingkat serta melakukan skrining agar penderita mendapat pengobatan yang cepat dan tepat. Mengingat tingginya prevalensi stres pada responden yang menderita hipertensi dan stres sebagai salah satu faktor yang mempengaruhi hipertensi, perlu dilakukan usaha-usaha dan intervensi misalnya dengan pengadaan posyandu lansia yang aktif dan rutin, promosi kesehatan pada kelompok usia ini, ataupun 
pembentukan kelompok yang mengadakan aktivitas bersama seperti senam, sekaa gong, dan lain-lain.

\section{DAFTAR PUSTAKA}

1. Supargo,dkk. Hubungan Stres dengan Penyakit Jantung Koroner. Medika 1989;331-338

2. JNC 7 Express. The Seventh Report of The Joint National Comitte on Prevention, Detection, Evaluation, And Treatment of High Blood Pressure, 2003:1-64.

3. National Institutes of Health: The Seventh Report of The Joint National Committee on Prevention, Detection, Evaluation, and Treatment of High Blood Pressure, NIH Publication, November 2003

4. Nozoe S. Stress and Hypertension. JMAJ 2002;188

5. Rafizar. Masalah Hipertensi dan Penanggulangannya. Majalah Kedokteran Indonesia 2000;50

6. Gunawan L. Hipertensi Tekanan Darah Tinggi, Penerbit Kanisius, Yogyakarta, 2001.

7. Sidabutar, R. P., Wiguno P. Hipertensi Essensial. In: IImu Penyakit Dalam Jilid II. Soeparman, Sarwono Waspadji. Balai Penerbit FK-UI, 1999. p: 205-222

8. Tierney LM, McPhee SJ, Papadakis MA. Systemic Hypertension. In : Current Medical Diagnosis \& Treatment. 41st Edition. McGraw-Hill Companies. 2002. p:459-469

9. Guidelines Committee (2003) European Society of Hypertension. European Society of Cardiology Guidelines for the Management of Arterial Hypertension. J. Hypertension 21: 1001-1053

10. Rundengan M. Hubungan antara Pekerjaan dan Stres Kerja dengan Kejadian Hipertensi pada Pekerja di Indonesia, 2005. Grafiti Medika Pers, MEDIKA, 2005;34(5):300.

11. Jacobs D. Physical Activity Reduces Hypertension Risk In Young Adults, 2007, Available from http://www.sciencedaily.com/releases/2007/03/

070320110911.htm Diakses pada tanggal 20 september 2013 